\title{
The Effect of Funding Cuts on the Utilization of an Oral Pathology Diagnostic Service
}

\author{
Deepika Chugh, R. John McComb, David Mock* \\ Faculty of Dentistry, University of Toronto, Toronto, Canada
}

\begin{abstract}
Deepika Chugh, R. John McComb, David Mock. The Effect of Funding Cuts on the Utilization of an Oral Pathology Diagnostic Service. International Journal of Oral Science, 1(3): 151-155, 2009
\end{abstract}

Aim To examine what impact the loss of funding had on the utilization of the oral pathology service.

Methodology Biopsy records were retrieved and examined in the two year period before and after the elimination of the subsidies in 2003.
Results After the loss of funding, there was a $31 \%$ decrease in the number of specimens submitted from practitioners in private practice, with the greatest drop noted in submissions from endodontists.

Conclusion Despite the immediate decrease in the number of biopsies submitted after the introduction of fee-for-service, the number of specimens being submitted appears to be on the rise again, as practitioners appear to recognize the value of a specialized oral pathology diagnostic service.

Keywords oral pathology, diagnostic services, funding

Document code: A $\quad$ CLC number: R780.2 Received May 7, 2009; Revision accepted Jul. 17, 2009

\section{Introduction}

Oral pathology diagnostic services are provided by a number of the dental schools within Canada (Priddy, 1984; Daley et al., 1992). Funding for such services varies amongst institutions. A survey by the Canadian Academy of Oral Pathology in 1992 revealed a majority of schools offered diagnostic services that were subsidized by the university, government, or other sources, with only one service charging a fee for service for specimens (Daley et al., 1992).

At the University of Toronto, the Toronto Oral Pathology Diagnostic Service (TOPS) is a nonprofit-making organization that has been providing diagnostic services for over 70 years (Organ and Main, 1976), within the Faculty of Dentistry as well as outside in the community. The oral pathologists employed by the service are licensed as specialists by the Royal College of Dental Surgeons of Ontario and are Fellows of the Royal
College of Dentists of Canada.

The maintenance of a school-affiliated biopsy service is essential for providing a teaching resource for students and residents, as well as continued faculty development (Schafer, 1960; Priddy, 1984; Tan and Siar, 1999).

Until April $1^{\text {st }}, 2003$, the TOPS provided a free diagnostic service to practitioners, and was largely subsidized by the University of Toronto's Faculty of Dentistry, with some assistance from the Ontario Cancer Treatment and Research Foundation. With increasing funding constraints, these subsidies were lost and a fee was charged to practitioners to help cover costs. Shafer (1960) reported that charging a fee for biopsies did not necessarily decrease the number of specimens submitted by clinicians. The purpose of this report was to examine the utilization of the TOPS in the two year period before and after the removal of the subsidies, in order to evaluate what impact the loss of funding had on the service. 


\section{Materials and Methods}

All biopsy records from 2001, 2002, 2004 and 2005 were retrieved from a computer database in the Department of Oral Pathology at the Faculty of Dentistry. The computer database was created with Microsoft Excel in 2001 and contains biopsy records for the service since 1986. Biopsy records from 2003 were excluded in the evaluation because this was the transition year. Specific information retrieved from the biopsy records for each year examined included total number of accessions, total number of diagnoses, number of specimens submitted based on location (i.e., hospital dental department, private practice, faculty, armed forces), number of specimens submitted by discipline and number of diagnoses made based on 23 diagnostic categories.

\section{Results}

During the four year period from 2001 to 2005 (excluding 2003), a total of 21,096 specimens were submitted, with a total of 21,960 diagnoses made. Table 1 shows the total number of accessions and diagnoses per year. From 2001 to 2002, there was a $4.4 \%$ increase in the number of accessions, but after the removal of the subsidy in 2003, a $29.5 \%$ decrease was noted in the number of accessions, with only a $1.4 \%$ increase in the number of accessions from 2004 to 2005.

Table 1 Total number of accessions and diagnoses from 2001-2004 (excluding 2003)

\begin{tabular}{lllll}
\hline & 2001 & 2002 & 2004 & 2005 \\
\hline of accessions & 5,980 & 6,246 & 4,403 & 4,467 \\
of diagnoses & 6,178 & 6,474 & 4,629 & 4,679 \\
\hline
\end{tabular}

More than $90 \%$ of specimens submitted were from private practice. Table 2 shows the number and percentage distribution of specimens based on location. After the elimination of the subsidy, there was a $31 \%$ decrease in the number of specimens received from private practice. The decrease in the number of specimens received from the faculty, consultations, and the hospital dental departments was not as dramatic. It should be noted that no charge was levied for accessions from these sources.

There was a generalized decrease in the number of specimens submitted from all disciplines from 2002 to 2004, with the exception of prosthodontics, where the numbers were too small to be significant. Table 3 shows the number and percentage

Table 2 Number and percentage distribution of specimens submitted based on location from 2001-2004 (excluding 2003)

\begin{tabular}{lllll}
\hline & \multicolumn{1}{c}{2001} & \multicolumn{1}{c}{2002} & \multicolumn{1}{c}{2004} & \multicolumn{1}{c}{2005} \\
\hline Hospital dental department & $218(3.6 \%)$ & $347(5.5 \%)$ & $299(6.7 \%)$ & $184(4.1 \%)$ \\
Faculty of dentistry & $92(1.5 \%)$ & $81(1.3 \%)$ & $78(1.8 \%)$ & $63(1.4 \%)$ \\
Private & $5,655(94.5 \%)$ & $5,816(92.2 \%)$ & $4,016(90.2 \%)$ & $4,214(93.7 \%)$ \\
Armed forces & $17(0.3 \%)$ & $5(0.08 \%)$ & $8(0.18 \%)$ & $7(0.16 \%)$ \\
Consultations & $3(0.05 \%)$ & $56(0.98 \%)$ & $52(1.2 \%)$ & $31(0.69 \%)$ \\
\hline
\end{tabular}

Table 3 Number and percentage distribution of specimens submitted by discipline (excluding 2003)

\begin{tabular}{lllll}
\hline & \multicolumn{1}{c}{2001} & \multicolumn{1}{c}{2002} & \multicolumn{1}{c}{2004} & \multicolumn{1}{c}{2005} \\
\hline General dentistry & $842(14.9 \%)$ & $920(14.9 \%)$ & $739(17.0 \%)$ & $642(14.5 \%)$ \\
Endodontics & $1,396(24.7 \%)$ & $1,497(24.2 \%)$ & $880(20.2 \%)$ & $885(19.9 \%)$ \\
Oral pathology & $5(0.09 \%)$ & $90(1.5 \%)$ & $15(0.34 \%)$ & $3(0.07 \%)$ \\
Oral surgery & $2,821(49.9 \%)$ & $3,056(49.4 \%)$ & $2,098(48.2 \%)$ & $2,204(49.7 \%)$ \\
Orthodontics & $0(0 \%)$ & $1(0.02 \%)$ & $0(0 \%)$ & $0(0 \%)$ \\
Pediatric dentistry & $9(0.16 \%)$ & $5(0.08 \%)$ & $3(0.02 \%)$ & $6(0.14 \%)$ \\
Periodontics & $577(10.2 \%)$ & $621(10.0 \%)$ & $615(14.1 \%)$ & $696(15.7 \%)$ \\
Prosthodontics & $2(0.04 \%)$ & $1(0.02 \%)$ & $1(0.02 \%)$ & $2(0.04 \%)$ \\
\hline
\end{tabular}


Table 4 Number and percentage distribution of diagnoses from 2001 to 2004 (excluding 2003)

\begin{tabular}{|c|c|c|c|c|}
\hline & 2001 & 2002 & 2004 & 2005 \\
\hline Inflammatory, mucosal & $2,068(33.5 \%)$ & $2,239(34.6 \%)$ & $1,664(35.9 \%)$ & $1,675(35.8 \%)$ \\
\hline Microbial disease & $70(1.1 \%)$ & $56(0.86 \%)$ & $52(1.1 \%)$ & $55(1.2 \%)$ \\
\hline Tooth, disease & $69(1.1 \%)$ & $58(0.9 \%)$ & $45(0.97 \%)$ & $39(0.83 \%)$ \\
\hline Periapical, inflammatory & $1,218(19.7 \%)$ & $1,324(20.5 \%)$ & $757(16.4 \%)$ & $770(16.5 \%)$ \\
\hline Benign neoplasms & $245(4.0 \%)$ & $248(3.8 \%)$ & $213(4.6 \%)$ & $236(5.0 \%)$ \\
\hline Pigmented, non-neoplastic & $54(0.87 \%)$ & $51(0.79 \%)$ & $49(1.1 \%)$ & $48(1.0 \%)$ \\
\hline Epithelial hyperkeratosis /hyperplasia & $478(7.7 \%)$ & $421(6.5 \%)$ & $393(8.5 \%)$ & $436(9.3 \%)$ \\
\hline Epithelial dysplasia & $185(3.0 \%)$ & $188(2.9 \%)$ & $151(3.3 \%)$ & $145(3.1 \%)$ \\
\hline Malignant neoplasms & $70(1.1 \%)$ & $67(1.0 \%)$ & $67(1.5 \%)$ & $67(1.4 \%)$ \\
\hline \multicolumn{5}{|l|}{ (excluding odontogenic /salivary) } \\
\hline Odontogenic tumours & $52(0.84 \%)$ & $65(1.0 \%)$ & $63(1.4 \%)$ & $44(0.94 \%)$ \\
\hline Salivary gland tumours - benign & $15(0.24 \%)$ & $18(0.28 \%)$ & $11(0.24 \%)$ & $15(0.32 \%)$ \\
\hline Salivary gland tumours - malignant & $7(0.11 \%)$ & $10(0.15 \%)$ & $6(0.13 \%)$ & $6(0.13 \%)$ \\
\hline Salivary gland diseases & $317(5.1 \%)$ & $320(4.9 \%)$ & $253(5.5 \%)$ & $271(5.8 \%)$ \\
\hline Vascular lesions & $37(0.6 \%)$ & $28(0.43 \%)$ & $37(0.80 \%)$ & $36(0.77 \%)$ \\
\hline Inflammatory, bone & $44(0.71 \%)$ & $52(0.80 \%)$ & $25(0.54 \%)$ & $31(0.66 \%)$ \\
\hline Bone disease & $28(0.45 \%)$ & $32(0.49 \%)$ & $14(0.30 \%)$ & $17(0.36 \%)$ \\
\hline Congenital lesions & $7(0.11 \%)$ & $2(0.03 \%)$ & $7(0.15 \%)$ & $5(0.12 \%)$ \\
\hline Cysts & $967(15.7 \%)$ & $1,001(15.5 \%)$ & $639(13.8 \%)$ & $615(13.1 \%)$ \\
\hline Metabolic disease & $3(0.05 \%)$ & $4(0.06 \%)$ & $1(0.02 \%)$ & $1(0.02 \%)$ \\
\hline Foreign body & $87(1.4 \%)$ & $107(1.7 \%)$ & $71(1.5 \%)$ & $61(1.3 \%)$ \\
\hline Other & $2(0.03 \%)$ & $2(0.03 \%)$ & $5(0.11 \%)$ & $6(0.13 \%)$ \\
\hline Normal tissue & $116(1.89 \%)$ & $140(2.2 \%)$ & $94(2.0 \%)$ & $81(1.7 \%)$ \\
\hline Non-reportable & $39(0.63 \%)$ & $41(0.63 \%)$ & $12(0.26 \%)$ & $19(0.41 \%)$ \\
\hline Total diagnoses & 6,178 & 6,474 & 4,629 & 4,679 \\
\hline
\end{tabular}

distribution of specimens submitted by discipline. Excluding oral pathology, the greatest drop (41.2\%) in the number of specimens submitted was seen from endodontists between 2002 and 2004. Interestingly, periodontics was the only discipline to show an increase in the number of specimens submitted from 2001 to 2005 .

The greatest decrease in the number of diagnoses made from 2002 to 2004 was seen in the periapical inflammatory category, with a $42.8 \%$ decrease in the number of diagnoses made. Table 4 shows the number and percentage of distribution of diagnoses.

\section{Discussion}

The number of specimens received by TOPS has increased over the years. In a study on the utilization of the TOPS by Organ and Main, the total number of accessions received in the eight month period between Nov. 1974 and Jun. 1975, was 1034 (Organ and Main, 1976).

From 2001 to 2005, the majority of accessions received were from private practice, in keeping with previous survey results of oral pathology services in Canada and the United States (Pullon and Miller,1977; Miller and Pullon, 1982; Priddy, 1984; Miller and Fantasia, 1988; Miller and Cleveland, 1992).

After the removal of the subsidy, there was an immediate decrease in the number of specimens submitted, particularly by endodontists. As a result, there was a corresponding decrease in the number of periapical inflammatory diagnoses made. Most endodontists submit specimens with a clinical diagnosis of periapical inflammatory disease, a benign process. The pathological diagnoses made for most of these specimen submissions confirm the practitioners' clinical impression, however, the potential for unexpected pathology cannot be ignored and reinforces the importance of submi- 
tting tissue for histological evaluation (Franklin and Jones, 2006). These results appear to contradict Shafer's suggestion that charging a fee for biopsies would not negatively impact the number of specimens submitted by clinicians. Alternatively, the results may reflect a difference between the two referral bases over the period when the fee was imposed.

Reassuringly, there was no change in the number of malignant diagnoses made after the removal of the subsidy, suggesting that practitioners continued to submit specimens with suspicions of malignancy, regardless of the fee associated with submitting the specimen.

The results do present some important questions:

\section{Where did practitioners send their biopsies?}

Practitioners may have sent specimens to private general laboratories for histological evaluation, where the fee charged for specimens is often less. Within Canada, many private laboratories based outside the university are staffed by general pathologists, who may not have the same level of experience in examining oral specimens as do oral pathologists. Oral pathologists are usually dentists who undergo a specialized training program in microscopic, radiologic and clinical diagnosis of pathologic conditions which affect the oral and maxillofacial area (American Academy of Oral and Maxillofacial Pathology, 2009).

Practitioners (e.g. oral surgeons) with hospital privileges may have opted to perform biopsies within a hospital setting, and sent the specimens for histological evaluation by the hospital-based pathologist. The services of the hospital pathologists are covered under the Ontario Health Insurance Plan (OHIP).

For difficult cases such as salivary gland lesions, odontogenic tumours, and mucosal lesions, a UK survey by Barret and Speight (1996) showed that general pathologists will refer to oral pathologists. Referral of cases by general pathologists in community hospitals and private laboratories make up the majority of consultations received at the TOPS. With the elimination of the subsidized diagnostic service, and practitioners seeking more cost-effective alternatives, it seemed more likely that specimens would be sent to private labora- tories and hospital-based laboratories, indirectly leading to an increase in the number of consultations received by TOPS. Interestingly, despite the decrease in the number of accessions following the removal of the subsidies, there did not appear to be the expected increase in the number of consultations.

The possibility that clinicians chose not to biopsy specimens, or even discard tissue must be raised. Failure to biopsy or submit tissue can lead to a delayed or even missed diagnosis, especially if the clinician's clinical impression is incorrect. The importance of microscopic examination cannot be underrated. All tissue removed during oral surgical procedures should be submitted for histological evaluation, regardless of the procedure, type of tissue, or clinical diagnosis (Franklin and Jones, 1992; Bricker et al.,1994).

\section{Why are general dentists submitting fewer specimens than specialists?}

In 1974/1975, Organ and Main reported that within the TOPS, general practitioners submitted more biopsies than any other group or specialty, approximately $48 \%$ of the total number of specimens received by the service (Organ and Main, 1976). Almost thirty years later, oral surgeons submitted more biopsies than general dentists or any other specialty.

General dentists often do not have the same comfort level, or level of training in clinical diagnoses and the performance of biopsies as other disciplines such as oral and maxillofacial surgery or periodontics. As a result, they may refer cases to specialists for consultation and subsequent biopsy (Diamanti et al., 2002). A survey of competency by Greenwood et al. reported that recently graduated dentists do not feel as well-prepared in performing biopsies as they do other dental procedures (Greenwood et al., 1998). Lopez-Jornet et al. assessed the attitudes of general dentists toward biopsy and found the most common reason for not performing biopsies was a lack of practical experience (Lopez-Jornet et al., 2007). Diamanti et al. suggested that general dentists are hesitant to perform biopsies for fear of misdiagnosis and subsequent legal action (Diamanti et al., 2002). Additional training is necessary (Priddy, 1984; 
Diamanti et al., 2002; Lopex-Jornet et al., 2007). However, there has been a lack of consensus regarding the methods that should be employed (Priddy, 1984).

A comparative analysis of utilization from other diagnostic services would be useful in evaluating emerging trends, but previous surveys of oral pathology diagnostic services across the United States and Canada are dated. New surveys need to be carried out to update the changes that are taking place among diagnostic services across North America.

\section{Conclusion}

There was an immediate decrease in the number of accessions after the loss of funding, however the submission of biopsies is gradually increasing with the number of accessions in 2008 climbing to 5,283 . It would appear that despite the loss of funding and introduction of fee-for-service, the TOPS has rebounded and continues to grow.

\section{Acknowledgements}

I would like to thank Dorothy Tsang and Maise Tung for their assistance in accessing the archives and providing historical information about the TOPS.

\section{References}

Priddy RW (1984). A survey of oral pathology biopsy services in Canadian dental schools. J Can Dent Assoc, 50(11): 829-832.

Daley TD, Wysocki GP, Main JH, Ahing S, Lovas JG (1992). Oral pathology in Canada: a survey. J Can Dent Assoc, 58(8): 647-652.

Organ G, Main JH (1976). Utilization of an oral pathology diagnostic service by dentists. J Can Dent Assoc, 42(11): 555-558.
Tan BH, Siar CH (1999). Oral tissue diagnostic services: a review of the literature. Annal Dent Univ Malaya, 6: 27-30.

Schafer WG (1960). A comparison of surveys of dental school biopsy services. J Dent Ed, 24: 298-303.

Pullon PA, Miller AS (1977). Survey of tissue diagnostic services in United States dental schools, 1953-1975. Oral Surg Oral Med Oral Pathol, 43(4): 579-582.

Miller AS, Pullon PA (1982). Survey of tissue-diagnostic services in United States dental schools, 1953-1980. Oral Surg Oral Med Oral Pathol, 53(6): 588-690.

Miller AS, Fantasia JE (1988). Survey of tissue-diagnostic services in United States dental schools-1985. Oral Surg, Oral Med, Oral Pathol, 65(2): 225-227.

Miller AS, Cleveland DB (1992). Survey of tissue diagnostic services in U.S. dental schools-1990. Oral Surg, Oral Med, Oral Pathol, 73(6): 717-719.

Franklin CD, Jones AV (2006). A survey of oral and maxillofacial pathology specimens submitted by general dental practitioners over a 30 -year period. $\mathrm{Br}$ Dent J, 200(8): 447-450.

American Academy of Oral and Maxillofacial Pathology. What is an oral and maxillofacial pathologist (OMP)? [www document] URL http://www.aaomp.org/residents /faq.php [accessed March 1, 2009].

Barret AW, Speight PM (1996). Use of oral pathology services by general histopathologists and their attitudes to training oral pathologists. J Clin Pathol, 49(7): 565569.

Bricker SL, Langlais RP, Miller CS (2001). Oral diagnosis, oral medicine, and treatment planning, 2nd ed. Hamiton: BC Decker Inc.

Diamanti N, Duxbury AJ, Ariyaratnam S, Marfarlane TV (2002). Attitudes to biopsy procedures in general dental practice. Br Dent J, 192(10): 588-592.

Greenwood LF, Lewis DW, Burgess RC (1998). How competent do our graduates feel? J Dent Educ, 62(4): 307-313.

Lopex-Jornet P, Velandrino-Nicolas A, Martinez-Beneyto Y, Fernandez-Soria M (2007). Attitude towards oral biopsy among general dentists in Murcia. Med Oral Patol Oral Cir Bucal, 12(2): E116-121.

*Corresponding author: David Mock

Address: Faculty of Dentistry, University of Toronto, Toronto, Canada

Tel: $0014169794910 \quad$ E-mail: david.mock@dentistry.utoronto.ca 